Social Relationship at Workplace ...

\title{
Research Article \\ Social Relationship at Workplace and Emotional Attachment of Employees: An Evidence of Pokhara Based Development Bank
}

\author{
Nabin Bahadur Adhikari \\ Faculty of Management, Janapriya Multiple Campus \\ Pokhara \\ Email: kazinabin@hotmail.com
}

\begin{abstract}
Effective social relationship at workplace and the emotional attachment is must for the survivable and betterment of the organization. This research paper aims to investigate employee social relationship at work and their emotional attachment with organization. For this regard hypothesis were set to test under some constraints. The study applied empirical approach in which a survey questionnaire was used to collect quantitative data and other statistical techniques like Chi square test, Pearson correlation was applied and conclude that employee commitment towards organization has some relationship to the social relationship at workplace. Additionally, the level of job involvement is associated with social relationship at workplace. Employee who is highly involved in job may not have the same proportion of level of social relationship at workplace.
\end{abstract}

Keywords: Commitment, emotional attachment, social relationship, work place

\section{Introduction}

It is believed that social relationships in the workplace also focus on employee feelings, attitudes, and perceptions. In organization, employee interacts with colleagues in the form of subordinates, peers or supervisors but feelings, attitudes and perceptions may be positive or negative. Hanpachern, Morgan \& Griego (1998) and Madsen et al. (2005) focused on 
Janapriya Journal of Interdisciplinary Studies, Vol. 6 (December 2017)

social relationships with employee readiness for change and found a significant correlation between them. This study also focuses on employee likes and dislikes and enjoyment related to talking, interacting and working in social relationships factor.

Bowlby(1969) and Ainsworth (1967) have stated that attachment is regarded to the personal development. It makes the claim that the ability for an individual to form an emotional and physical "attachment" that gives a sense of stability and security necessary to take risks, branch out, and grow and develop. Emotional attachment is related to the affective aspect of the individual. Hence it is concerned with the feeling of pride and personal sense of obligation to perform their duties within the organization. It is developed by work experience such as job challenge, degree of autonomy, and a variety of skills. (Dunham, Grube, Castaneda, 1994).

An emotionally attached employee gets fully engaged with the organization. High levels of engagement promote retention of talent, foster customer loyalty and improve organizational performance and stakeholder value (Lockwood, 2007). Employees remain enthusiastic about their company; feel valued for the contributions they make to the organization and not just for the salary they receive. In a survey conducted by gallop organization (2004) it is found that top $24 \%$ of businesses experienced less turnover, higher levels of profitability, increased revenues and greater customer loyalty due to higher level of employee engagement (Gill, 2009).

Engagement is influenced by many factors ranging from workplace culture, organizational communication and managerial styles to trust, respect, leadership and company reputation (Lockwood, 2007).

With the direction of NRB many banks and FIs have merged together and most of them are in pipeline for this process. OM Development Bank is the result of the merger of Bishow Bikash Bank and Fewa Finance Company limited. The major objective of this research work is to identify the level of social relationship of worker at workplace and their emotional attachment. This research work tries to acquire the answer of the following questions: 
Social Relationship at Workplace ...

- Is there any correlation between social relationship at workplace (SRW) and employee commitment towards organization (ECO)?

- What sort of relationship does Job Involvement and social relationship at workplace has?

The hypothesis of the study was;

H1: There is no correlation between social relationship in workplace and employee commitment towards organization.

H2: There is no correlation between Job Involvement and social relationship in the workplace.

\section{Data and Methods}

OM Development Bank is formed after the merger of Fewa Finance Company(FFinance) and Bishow Bikas Bank(BBBank). This study was conducted in Fewa Bikas Bank before merger where all the staffs from head office and its branches are included. The total population number of staff presently working in the bank is 229 after the merge. Before the merge there were 112 employees at BBBank with 14 branches and 117 employees at FFinance with its 16 branches.

These banks were selected due to the easiness because there head offices were located in Pokhara. For this empirical study, a random sampling has been done from the staffs of Fewa Bikas Bank (formed after the merger of BBBank and FFinance Co. Ltd). The targeted participants of the main survey were the staff of the Fewa Bikas Bank which is formed after the merger of BBBank and FFinance Co. Ltd. 50-50\% of total number of population of both the institutions was taken as a sample size. Non probability accidental sampling technique was used for selecting samples.

The Survey was used for collecting the first hand data. The procedure adopted for this survey follows a quantitative approach (descriptive research design) has been used to determine the relationship among the variables. The major source of data and information used for this study is 
Janapriya Journal of Interdisciplinary Studies, Vol. 6 (December 2017)

primary sources. The data are collected through survey questionnaire method.

Questionnaires along with the covering letter were sent to the staff through the email and personal visit. Email addresses of the staff were obtained from the IT Head of the institution. All the questionnaires were closed ended. Demographic information's were collected using nominal question method with number of options to choose. Meanwhile, the secondary data have been obtained through the related websites, report, journals, articles, magazines and others.

Statements that measure the respondent's perceptions were developed using a five points Likert scale. A Likert scale was chosen because respondents can explicitly understand it and scale discriminates well between perceptions respondents; their degree of agreement or disagreement.

Based on quantitative data, both descriptive and exploratory analysis was done using the IBM SPSS Statistics version 21 for the preparation of this article. Frequencies, means and standard deviations as descriptive analyses were used to describe the samples. Beside this, the Cronbach's alpha coefficient (to determine the internal consistency), Kurtosis and Skewness, Chi- Square Test and Pearson Correlation techniques were used for the further data analysis. Normality test of major variables (SRW and EA) were done in order to determine whether the data collected were normally distributed or not. Kurtosis and Skewness, K-S and S-W tools were used for the determination of parametric and non-parametric data. Meanwhile, Cronbach's alpha coefficient of major variables was computed in order to determine the internal consistency and reliability among the items within the each variable.

\section{Results and Discussion}

The data collected from the sample are presented in the following table followed by the description of data mentioned in the table. 
Social Relationship at Workplace ...

\section{Table 1}

\section{Demographic Characteristics}

\begin{tabular}{|c|c|c|c|}
\hline Characteristics & Category & Frequency & Percentage \\
\hline Previous Organization & $\begin{array}{l}\text { Bishwa Bikas } \\
\text { Bank } \\
\text { Fewa Finance Co. } \\
\text { Ltd }\end{array}$ & $\begin{array}{l}25 \\
25\end{array}$ & $\begin{array}{l}50 \\
50\end{array}$ \\
\hline Gender & $\begin{array}{l}\text { Male } \\
\text { Female }\end{array}$ & $\begin{array}{l}37 \\
13\end{array}$ & $\begin{array}{l}74 \\
26\end{array}$ \\
\hline Age & $\begin{array}{l}\text { Below } 21 \\
\text { Below } 40 \\
40+\end{array}$ & $\begin{array}{l}1 \\
45 \\
4\end{array}$ & $\begin{array}{l}2 \\
90 \\
8\end{array}$ \\
\hline Marital Status & $\begin{array}{l}\text { Married } \\
\text { Unmarried }\end{array}$ & $\begin{array}{l}33 \\
17\end{array}$ & $\begin{array}{l}66 \\
34\end{array}$ \\
\hline Number of Dependent in Family & $\begin{array}{l}1-2 \\
3-4 \\
5 \text { and above }\end{array}$ & $\begin{array}{l}10 \\
21 \\
18\end{array}$ & $\begin{array}{l}20.4 \\
42.9 \\
36.7\end{array}$ \\
\hline Highest Education Level & $\begin{array}{l}\text { Master's and } \\
\text { above } \\
\text { Bachelor Degree } \\
\text { Intermediate } \\
\text { Degree }\end{array}$ & $\begin{array}{l}25 \\
19 \\
5\end{array}$ & $\begin{array}{l}51 \\
38.8 \\
10.2\end{array}$ \\
\hline $\begin{array}{l}\text { Number of Years Worked in } \\
\text { Previous Post }\end{array}$ & $\begin{array}{l}\text { Less than } 1 \text { year } \\
1-5 \text { years } \\
6 \text { years and above }\end{array}$ & $\begin{array}{l}10 \\
30 \\
10\end{array}$ & $\begin{array}{l}20 \\
60 \\
20\end{array}$ \\
\hline $\begin{array}{l}\text { Number of Years Worked with } \\
\text { Previous Employer }\end{array}$ & $\begin{array}{l}\text { Less than } 1 \text { year } \\
1-5 \text { years } \\
6 \text { years and above }\end{array}$ & $\begin{array}{l}7 \\
30 \\
13\end{array}$ & $\begin{array}{l}14 \\
60 \\
26\end{array}$ \\
\hline
\end{tabular}


Janapriya Journal of Interdisciplinary Studies, Vol. 6 (December 2017)

\begin{tabular}{llll}
\hline Characteristics & Category & Frequency & Percentage \\
\hline \multirow{3}{*}{ Present Position at Organization } & Managerial Level & 4 & 8.5 \\
& Officer Level & 18 & 38.3 \\
& Assistant Level & 23 & 48.9 \\
& Supportive Level & 2 & 4.3 \\
& & & \\
& & & 8.5 \\
Position in Previous & Managerial Level & 4 & 29.8 \\
Organization & Officer Level & 14 & 55.3 \\
& Assistant Level & 26 & 6.4 \\
& Supportive Level & 3 & \\
& & & \\
& & 37 & 78.7 \\
Number of Times Exposed to & First time & 9 & 2.1 \\
Organizational Changes & More than second & 1 & \\
& time & &
\end{tabular}

Note: Total number of sample was 50 including Missing data.

Source: field survey, 2016

The characteristics such as age, gender, marital status, present employment status, past employment status, higher education level, number of dependents, years in previous position and years with previous employer and the number of times exposed to the changes like merger were asked to the respondents in the questionnaire. Of the total respondents $(50 \%, \mathrm{n}=25)$ were previously employee at BBBank and $(50 \%, \mathrm{n}=25)$ were previously employee at FFinance Co. Ltd. Majority of the participant were male (74\%, $\mathrm{n}=37)$ with the age group 21-40 $(90 \%, \mathrm{n}=45)$. The majority of the participant were married $(66 \%, \mathrm{n}=33)$ and the number of dependent mostly lies at 3-4 $(42.9 \%, n=21)$. About $51 \%$ of had more than Master's Degree $(n=25)$ as the highest level of education which is followed by the Bachelor's Degree with $38.8 \%$. Majority of the participants are working as Assistant level at previous position $(48.9 \%, n=23) .60 \%(n=30)$ employee worked 1-5 years with the previous employer and likewise $60 \% \quad(n=30)$ employee worked 1-5 years in the previous post. Likewise the participants who worked as assistant position at previous organization has the majority $(55.3 \%, \mathrm{n}=26)$. Most of the participants $(78.7 \%, \mathrm{n}=37)$ reported that they 
Social Relationship at Workplace ...

were exposed to such kind of the changes like merger, structural change, for the first time.

\section{Social Relationship at Workplace}

Social relationship in the workplace focuses on employee feelings, attitudes and perceptions. It includes employee interaction with colleagues in the form of subordinates, peers or supervisors that may be positive or negative.

A Pearson product- moment correlation coefficient was conducted to evaluate the null hypothesis that there is no relationship between SRW and ECO $(\mathrm{N}=49)$. Preliminary analysis showed that there were no violations in the assumptions of normality. There was significant evidence to reject the null hypothesis and conclude that there was a medium, positive association between ECO $(\mathrm{M}=3.2623, \quad \mathrm{SD}=0.37702)$ and SRW $(\mathrm{M}=3.9184$, $\mathrm{SD}=0.36654), \mathrm{r}(48)=0.341, \rho<0.05$. Hence, the social relationship at work place is associated with employee commitment towards organization to the low level.

Table 2

Mean and Standard Deviation of ECO and SRW

\begin{tabular}{lccc}
\hline \multicolumn{1}{c}{ Variables } & Mean & Std. Deviation & N \\
\hline Mean of ECO & 3.2623 & 0.37702 & 50 \\
Mean of SRW & 3.9184 & 0.36654 & 49 \\
\hline
\end{tabular}

Source: field survey, 2016

Table 3

Pearson Correlation of ECO and SRW

\begin{tabular}{lc}
\hline Test Measures & Value \\
\hline Pearson Correlation & 0.341 \\
Significance (2-tailed) & 0.016 \\
\hline
\end{tabular}

Note: Correlation is significant at the 0.05 level (2-tailed) 
Janapriya Journal of Interdisciplinary Studies, Vol. 6 (December 2017)

\section{Emotional Attachment}

Emotional attachment is the feeling of pride and personal sense of obligation to perform their duties within the organization. It is related to the affective aspect of the individual. There were 7 items that were been used to measure the emotional attachment of the employee.

A Pearson product- moment correlation coefficient was conducted to evaluate the null hypothesis that there is no relationship between SRW and JI $(\mathrm{N}=49)$. Preliminary analysis showed that there were no violations in the assumptions of normality. There was significant evidence to reject the null hypothesis and conclude that there was a small, positive association between JI $(\mathrm{M}=3.7366, \mathrm{SD}=0.35589)$ and SRW $(\mathrm{M}=3.9184, \mathrm{SD}=0.36654)$, r $(48)=0.285, \rho<0.05$. Hence, level of Job Involvement is associated with Social Relationship at workplace to the low level.

\section{Table 4}

Mean and Standard Deviation of SRW and JI

\begin{tabular}{lccc}
\hline \multicolumn{1}{c}{ Variables } & Mean & Std. Deviation & N \\
\hline Mean of SRW & 3.9184 & 0.36654 & 49 \\
Mean of JI & 3.7366 & 0.35589 & 49 \\
\hline
\end{tabular}

\section{Table 5}

\section{Pearson Correlation of SRW and JI}

\begin{tabular}{lc}
\hline Test Measures & Value \\
\hline Pearson Correlation & 0.285 \\
Significance (2-tailed) & 0.047
\end{tabular}

Note: Correlation is significant at the level 0.05 level (2-tailed)

\section{Conclusion}

There is no correlation between social relationship in workplace and employee commitment towards organization, so Null hypothesis is rejected. As an answer to the research question $1^{\text {st }}$ the social relationship at work place is associated with employee commitment towards organization to the low level. It shows that employee commitment towards organization has some relationship to the social relationship at workplace. Employee who is 
Social Relationship at Workplace ...

highly committed towards the organization may not have same proportion of level of social relationship at workplace.

There is no correlation between Job Involvement and social relationship in the workplace that's why the Null hypothesis is again rejected or accepts the alternative hypothesis. The conclusion of research is that the level of Job Involvement is associated with Social Relationship at workplace to the low level. Employee who is highly involved in job may not have the same proportion of level of social relationship at workplace.

\section{Acknowledgment}

I am highly indebted to Professor Dr. Vikash Kumar KC. for stimulating me continuously for the preparation of research paper and for his immense support in reviewing this paper.

\section{References}

Ainsworth, M. (1967). Infancy in Uganda: Infant Care and the Growth of Love. Baltimore: John Hopkins University Press

Bowlby,J.(1969). Attachment and Loss. [Online]. Available:

<http://www.psychologistworld.com/developmental/attachmenttheory.php> [2015, October 10].

Dunham, R.B., Grube, J.A. \& Castañeda, M.B. (1994). Organizational commitment: The utility of an integrative definition. Journal of Applied Psychology, 79(3), 370-380.

Gill, A. (2009). Employee engagement in a change environment. Stragetic HR Review, 8(2), 19-2.

Hanpachern, C., Morgan, G.A. \& Griego, O.V. (1998). An extension of the theory of margin: A framework for assessing readiness for change. Human Resource Development Quarterly, 9(4), 339. 